\title{
Fourth International Locust Conference
}

$\mathrm{T}$ HE International Locust Conferences are held at intervals of two to three years in order to take stock of the progress made in anti-locust research in different countries and to discuss the plans for further concerted action. The Fourth Conference took place at Cairo two years ago, in April 1936, but a full account of its proceedings has appeared only recently*.

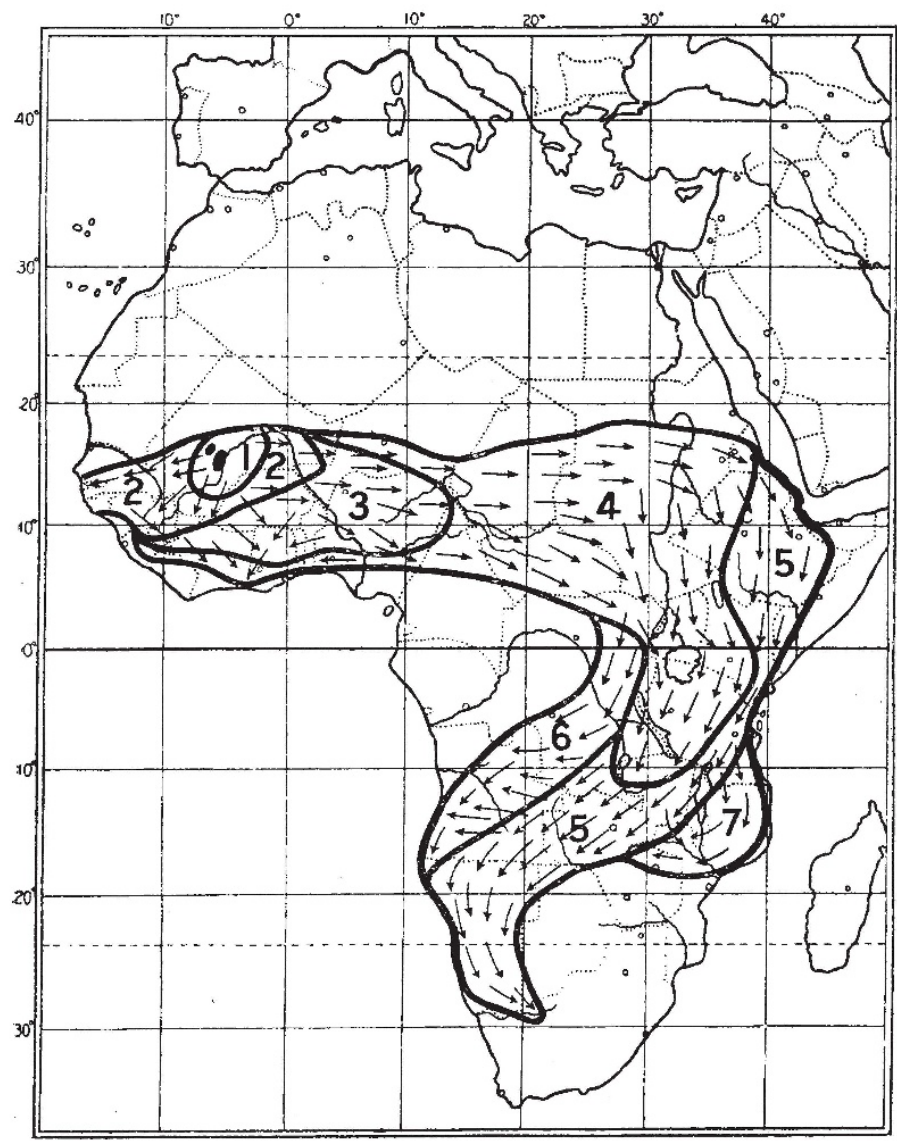

SPREAd OF THE AFRICAN MIGRATORY LOCUST The outbreak originated in 1928 in areas marked by two spots in zone 1, which was invaded during the first year. Zones 2, 3 , 4, etc., represent the expansion of the invasion in each of the following years up to 1934. Arrows indicate the main diroctions of migration.

The Conference proved the world-wide interest in the locust problem, since twenty-three countries were represented (as against thirteen which took part in the Third Conference held in London in 1934), and more than fifty communications were made. The statistical data on the losses caused by locusts in some of the countries were of great interest; the United States reported losses during the ten year period 1925-34 amounting to about 245 million dollars, and Canada to about 36 millions, while more

* Proceedings of the Fourth International Locust Conference, Cairo April 22, 1936. Pp. $96+51$ appendixes. (Cairo: Government Press, 1937.) than 4.5 millions were spent on control in the firstnamed country, and nearly 3.5 millions in the second. Even more staggering figures were presented by the Union of South Africa, where two years of invasion by the red locust cost the country $£ 943,500$. Similar statistics collected for all countries suffering from locusts would undoubtedly show that this pest well deserves the attention recently paid to devising better means of controlling it. The Conference entrusted the Imperial Institute of Entomology with the regular collection of such statistical data in future.

The central problem discussed by the Conference was that of the recent progress in the study of the phases in locusts and its practical application. It was agreed that the phenomenon of phase transformation provides a trustworthy basis on which to frame a sound policy for the prevention of outbreaks of locusts and grasshoppers. With regard to the African migratory locust (Locusta migratoria migratorioides $\mathbf{R}$, and $\mathbf{F}$.), the data obtained as the result of international investigations centred at the Imperial Institute of Entomology were particularly convincing since the present invasion has been shown to originate in very restricted areas in the inundation zone of the Middle Niger, in the French Sudan. This happened about the year 1928, and in seven years nearly the whole of tropical Africa was overrun by swarms, as is shown in the accompanying map. This evidence induced the Conference to recommend to the Governments of the countries concerned to enter into dis. cussion on the ways and means for the establishment of a permanent organization for the prevention of invasions of this locust in future, by keeping its outbreak areas under expert supervision and by suppressing all incipient swarms. A similar state of affairs was found to exist with regard to the two other African locusts, the red locust (Nomadacris septemfasciata Serv.) and the desert locust (Schistocerca gregaria Forsk.), although the investigations on these species were at that time not sufficiently advanced for practical steps to be taken.

Another outstanding event of the Cairo Conference was the discussion of the problem as to what extent such activities as agriculture and grazing affect the distribution and mass appearance of locusts and grasshoppers. It was commonly believed, even by some entomologists, that these insects constitute a danger only in the countries with a low level of agriculture, and that their outbreaks become less severe as the country is more highly developed. The evidence presented, particularly by the delegates from North America, led the Conference to the conclusion that, on the contrary, in the case of many species of locusts and grasshoppers, their excessive multiplication and spread have been furthered rather 
than hindered by man's activities. Therefore, no hope can be entertained for the locust and grasshopper problem becoming less acute merely as a result of a general development of a country. The Conference suggested that particular attention should be paid in all future investigations to the influence on the life and ecology of locusts and grasshoppers of the various forms of human activity, such as agriculture, pastoral activity, deforestation, grass fires, etc.
All the aspects of the general theory of locust outbreaks, and most of the regional problems were discussed by the Conference, which embodied the results of discussions in twenty-five resolutions and four recommendations, based on the facts presented in the papers printed as appendixes to the proceedings, forming a large volume of nearly 500 pages.

The next, the Fifth International Locust Conference, will be held at Brussels in August this year.

\title{
Numerical Changes in the German Student Body
}

\author{
By Dr. E. Y. Hartshorne, jun., Tutor in Sociology, Harvard University
}

$\mathrm{O}^{\mathrm{F}}$ FFICIAL figures for the student body in the German Reich are available up to and in. cluding the academic year 1936-37. Frequent alteration in methods of classification and description have obscured the nature of some of the changes and make it difficult and sometimes impossible to interpret them. Only the less equivocal figures are here discussed. For the academic years 1932--33, 1933-34 and 1934-35, these are taken from the official Deutsche Hochschulstatistik, vols. 10-14; for 1935-36 from the official Die Deutschen Hochschulen vol. 1 (vol. 2 for 1936-37 either has not appeared or is inaccessible in the United States and Great Britain); for 1936-37 from the Statistisches Jahrbuch für das Deutsche Reich of 1937. There is reason to believe that the tendencies described below have continued in the academic year 1937-38.

In what follows there are included as 'students' all registered as such, except (a) 'auditors', that is those not committed to any definite course or examination, and (b) foreign students, except where specially indicated.

The decrease in the number of students is largely, but not entirely, conditioned by National Socialist policy. There are three obvious factors which have produced a fall in numbers. First, the number of young men in the German population of an age to enter the universities has probably fallen somewhat during these years. Secondly, since 1934 a limit has been set to the numbers admissible to a university education. Thirdly, Jews and so-called 'non-Aryans' have been practically excluded and the proportion of women students has been nominally fixed. The decrease, however, has been much sharper than can be explained by the action of these factors alone.

TABLE 1. NUMBERS OF STUDENTS IN ALL GERMAN Hochschulen (UNIVERSITIES, COILLEGES OF ENGINEERING, MINING AND AGRICULTURE, AND SCHOOLS FOR TEACHERS AND FOR CATHOLIO THEOLOGY)

\begin{tabular}{|c|c|c|c|}
\hline Winter Term & Men & Women & Both \\
\hline $1932-33$ & 97,576 & 18,578 & 116,154 \\
$1933-34$ & 91,263 & 15,501 & 106,764 \\
$1934-35$ & 76,961 & 12,132 & 89,093 \\
$1935-36$ & 70,462 & 10,976 & 81,438 \\
$1936-37$ & 57,672 & 9,410 & 67,082 \\
\hline
\end{tabular}

Thus in the winter term of 1936-37 the total number of students was only $5.7 \cdot 8$ per cent of the number enrolled before the National Socialist seizure of power in 1933. "Coming events cast their shadows before" since in the academic year 1932-33 this deoline had already begun.
In the field of science, the accompanying graph shows the development of enrolment for the major groups: (1) agriculture, (2) engineering, (3) natural sciences with mathematics, and (4) medical sciences.* The sharp decline of entry in the last three of these practical fields is puzzling. It is easily intelligible that the National Socialist emphasis on

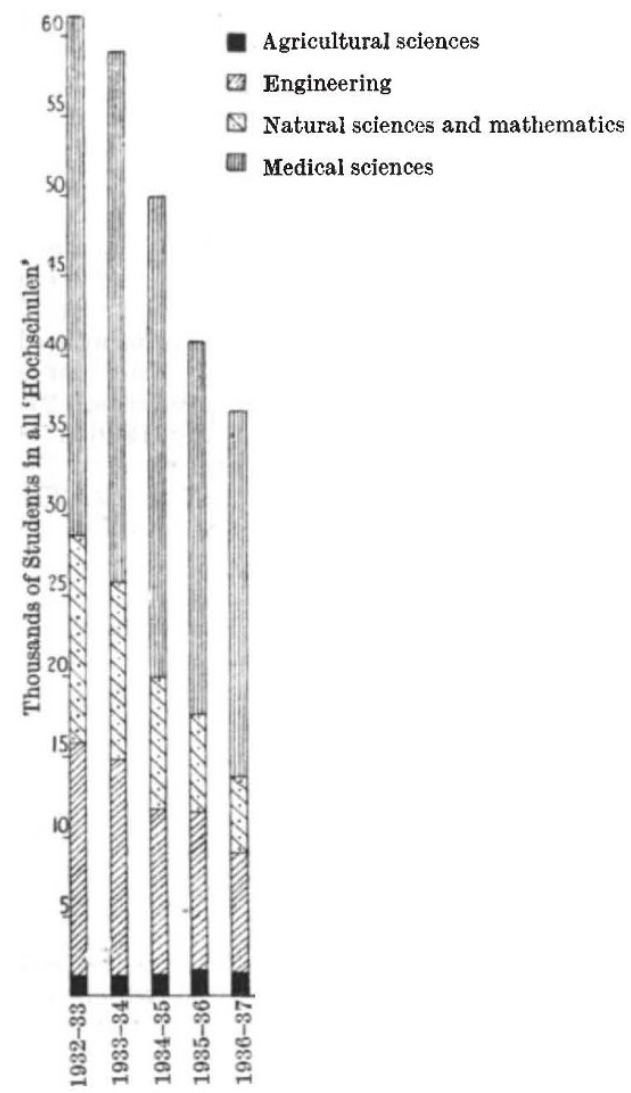

increased production from native soil should have raised the number in the agricultural sciences (1,356 in $1932-33$ to 1,477 in $1936-37)$ and also have raised the proportion of students of agriculture to the total entry of students (from $1 \cdot 2$ to $2 \cdot 2$ per cent).

* In the category of medical sciences are here included dentistry, veterinary surg $\mathrm{ry}$ and pharmacy. 